\title{
AUTONOMIA DO ALUNO DE EAD NO PROCESSO DE ENSINO E DE APRENDIZAGEM
}

Autonomy in the Student of EAD in the Process of Teaching and Learning

\author{
Karina Roberta Baseggio \\ Eray Proença Muniz
}

\section{Resumo}

A Educação a Distância (EAD) é uma modalidade de ensino que prevê a construção da autonomia do aluno no processo de ensino e de aprendizagem. Este artigo objetiva levantar aspectos dessa questão na bibliografia estudada e ainda verificar em que medida os estudantes envolvidos na pesquisa apresentam habilidades que os identificam autônomos em seu processo de aprendizagem. Os procedimentos metodológicos foram: revisão bibliográfica, levantamento da situação da EAD em São Gabriel do Oeste/MS, observação e aplicação de questionário com perguntas relacionadas à atuação dos estudantes nessa modalidade de ensino. Foram envolvidos cinco alunos de cursos diferentes e em variados graus de estudo. Constatou-se que a autonomia desses estudantes é parcial, uma vez que os mesmos apresentaram apenas algumas das habilidades que indicam autonomia no processo de aprendizagem. A expectativa é que esse resultado possa auxiliar as instituições conceptoras de cursos em EAD a direcionar procedimentos que viabilizem o alcance dessas habilidades em seus alunos.

Palavras-chave: Educação a Distância; Autonomia; Aluno.

\section{Abstract}

Distance Education (EAD) is a form of teaching that enables the student to build autonomy in the process of teaching and learning. This article aims at identifying aspects of this issue in the literature that has been studied, and also 
at determining to what extent students involved in research show the skills that identify them as autonomous. The methodological procedures adopted were: literature review, survey of the EAD situation in São Gabriel do Oeste, state of Mato Grosso do Sul, observation and the application of a questionnaire with questions related to the performance of students prepared according to this way of teaching. Five students from different courses and at several levels of study were involved. It was found that student autonomy is partial, insofar as students presented few skills that could indicate autonomy in the learning process. This result might be helpful for EAD course-preparing institutions to channel procedures that will allow their students to achieve this level.

Keywords: Distance Education; Autonomy; Student.

\section{Introdução}

A educação a distância (EAD) é uma modalidade de ensino que prevê a construção da autonomia do aluno no processo de ensino e de aprendizagem. Essa modalidade encontra-se em expansão no Brasil e insere em seu contexto a ideia de flexibilidade na forma de estudar. Os alunos que buscam essa modalidade, em grande parte são compostos por adultos trabalhadores, geralmente, sem condições de frequentar cursos presenciais.

Os alunos de EAD estão diante de uma nova realidade educacional, que difere bastante do ensino presencial, especialmente por valorizar a questão da autonomia dos estudantes, isto é, por prescindir a presença constante de um professor.

A ênfase na questão da autonomia exige dos estudantes habilidades muitas vezes inexistentes na maioria desses alunos, mas que podem ser adquiridas com dedicação, interesse e compromisso nos estudos.

A motivação, a autoconfiança e a participação do aprendiz são condições sine qua non do sucesso nos estudos em EAD. O aluno precisa realmente envolver-se com o curso (BELLONI, 1999; PRETI, 2000).

Para Belloni (1999), no processo de aprendizagem autônoma, o estudante não é objeto ou produto, mas sujeito ativo que realiza sua própria aprendizagem e abstrai o conhecimento aplicando-o em situações novas.

Ainda para a mesma autora, o conceito de aprendizagem autônoma implica uma dimensão de autodireção e autodeterminação que não é 
facilmente realizada por muitos estudantes de EaD, uma vez que sem o auxílio direto do professor o aluno precisa estudar sozinho e ser o responsável por seu processo de aprendizagem.

A imagem de uma aprendizagem passiva e individualizada ao ponto de se tornar solitária desafia a criatividade dos conceptores de cursos e de educadores em EaD, pois enquanto alguns alunos vêem nesses cursos uma oportunidade de conciliar sua rotina diária com o estudo, outros ficam perturbados pelo conflito que se cria com a visão do estudo como sinônimo de isolamento (BELLONI, 1999).

A autonomia implica, ainda, a questão da criatividade, já que os próprios alunos podem montar grupos de estudo para evitar o isolamento na hora de estudar.

Enfim, nota-se que o contexto de aprendizagem autônoma em EAD ainda carece de muitas pesquisas, pois, conhecer como os estudantes conduzem esse processo individualizado de aprendizagem é um dos grandes desafios.

No município de São Gabriel do Oeste - MS, possivelmente, este seja o primeiro trabalho de pesquisa em que se propõe discutir a autonomia no processo de ensino e de aprendizagem dos alunos de EaD. Assim, este artigo objetiva levantar aspectos dessa questão na bibliografia e ainda, verificar em que medida os estudantes envolvidos na pesquisa apresentam habilidades que o identificam autônomos.

\section{A Educação a Distância}

Segundo Moran (2002), a Educação a Distância é um processo de ensinoaprendizagem mediado por tecnologias em que professores e alunos estão separados espacial e temporalmente, sendo fundamental a autonomia do aluno e a interação com os demais envolvidos.

Conforme Preti (2000), a EaD é uma modalidade de ensino que utiliza meios adequados para atingir um grupo seleto de pessoas e que alcança destaque por criar, por intermédio das tecnologias, novas situações de aprendizagem como a atuação de um único professor em uma turma de centenas de alunos e por realizar um estudo mais flexível e criativo que oferece alternativas à realidade do trabalhador e o auxilia em sua autoaprendizagem. 
Para Belloni (2003) a interação mediatizada (professor/aluno; estudante/estudante) e a interatividade com os materiais de boa qualidade, torna-se uma prática que motiva a aprendizagem a qual pode desenvolver nos estudantes as habilidades de autonomia.

\section{Educação a Distância em São Gabriel do Oeste - MS}

Em São Gabriel do Oeste a EAD teve sua gênese no ano de 2001, por meio de um convênio com o Núcleo de Ensino a Distância da UFMS, o município passou a ser um Centro de Apoio da Universidade. Naquela ocasião realizouse o primeiro vestibular, Pedagogia - Séries Iniciais que iniciou em 2002, com 80 alunos, destes, 72 concluíram o curso.

Em 2004, teve início a segunda turma desse mesmo curso, com 100 alunos matriculados, destes, 76 alunos concluíram.

Em 2005, o município recebeu o título de Pólo da Universidade Aberta do Brasil (UAB) e teve início a terceira turma do Curso de Pedagogia - Séries Iniciais - 100 vagas; havendo a matrícula de 96 alunos.

Em 2006, implantaram-se os cursos de Biologia - convênio Consórcio Setentrional - 60 vagas, 44 alunos matriculados; Pedagogia- Educação Infantil - Consórcio Pró-Formar - 60 vagas, 25 alunos matriculados; Administração - Projeto-Piloto da UAB - 125 vagas, 58 alunos matriculados.

Em 2007, iniciou o segundo Projeto-piloto da UAB, turma de Administração-150 vagas, 123 alunos matriculados.

Em 2008 a UAB em parceria com a UFMS ofereceu os cursos de: LetrasPortuguês/Espanhol - 50 matriculados; Matemática - 48 matriculados; Pedagogia - Educação Especial - 34 matrículas e tendo parceria com a Universidade Federal de Santa Catarina (UFSC) ofereceu o curso de Ciências Contábeis - 50 alunos matriculados.

Atualmente, oito cursos de graduação estão em andamento no município, com nove turmas em funcionamento: Pedagogia - Séries Iniciais, 74 alunos; Administração - turma um, 67 alunos, turma dois, 46 alunos; Biologia 26 alunos; Pedagogia - Educação Infantil, 20 alunos; Letras Português/Espanhol, 27 alunos; Matemática 24 alunos; Pedagogia Educação Especial, 25 alunos e Ciências Contábeis com 16 alunos. 
Ressalta-se que cada curso apresenta uma metodologia específica e são utilizados recursos que visam a maximização do processo de ensinoaprendizagem.

Com relação aos cursos analisados na pesquisa observaram-se algumas características:

Biologia- auxílio constante do tutor; $n^{\circ}$ reduzido de aulas presenciais (geralmente uma vez por mês); interação on-line disponível.

Matemática- auxílio reduzido do tutor; $\mathrm{n}^{\circ}$ maior de aulas presenciais (geralmente três vezes por mês); interação on-line disponível.

Administração- auxílio reduzido do tutor; $\mathrm{n}^{\circ}$ reduzido de aulas presenciais (geralmente uma por mês); interação on-line disponível.

Pedagogia - Séries Iniciais- não há tutor; aulas presenciais freqüentes (geralmente todo final de semana); não há interação on-line.

\section{Habilidades do Aluno de EaD - Autonomia no Processo de Ensino e Aprendizagem}

Em sua etimologia, autonomia vem do grego autós (próprio, a si mesmo) e nomos (lei, norma, regra). Para os gregos esse termo significava a capacidade de cada cidade em se autogovernar, de elaborar seus preceitos, suas leis e dos cidadãos decidirem o que fazer (PRETI, 2000).

Na relação pedagógica, a autonomia está associada ao reconhecer no outro a capacidade de participar, ter o que oferecer e poder decidir aliado ao potencial do sujeito em "tomar para si" sua própria formação, (op.cit).

Conforme a discussão de Pretti (2000) entende-se que a autonomia está relacionada ao próprio indivíduo, à sua capacidade de buscar por si mesmo, sem uma dependência explícita de outrem. Neste aspecto reconhecer a "autonomia" no processo de ensino e de aprendizagem, significa entender que o outro é independente, capaz de pesquisar sozinho e que o professor e/ou tutor é o mediador do processo de aprendizagem.

Assim, constata-se que a questão da autonomia no processo de ensino e de aprendizagem dos estudantes de EAD parece não ser tão simples, pois essa modalidade exige mudanças na rotina dos alunos. A independência na hora de estudar é o fator principal e assim, somente terão bom aproveitamento aqueles que conseguirem ser gestores do seu tempo e, 
praticarem hábitos adequados de estudo, o que envolve disciplina, interesse, motivação, observância de prazos entre outros.

De acordo com Belloni (1999), é possível perceber que a autoaprendizagem é uma tarefa pessoal que exige disciplina, isto é, o aluno precisa ser extremamente responsável com seu horário de estudos e pressupõe-se também que o aprendiz deve participar coletivamente na interaprendizagem e compartilhar saberes e experiências.

No entendimento de Preti (2000), a autoaprendizagem, está diretamente relacionada a autonomia do estudante de EAD no seu processo de aprendizagem e deve ser buscada, exercitada e integrada no cotidiano das atividades profissionais e pessoais para que se torne algo próprio do sujeito.

De acordo com as afirmações dos autores fica subentendido que para o aluno ser considerado autônomo ele deve possuir o máximo de habilidades que facilitam a autoaprendizagem. Ao contrário, a autonomia será parcial ou nula, o que dificultará a atuação do aluno nessa modalidade de ensino ou causará sua desistência pelo fato do aluno não ter perfil e dedicação suficientes para adequar-se a essa forma diferenciada de aprendizado.

\section{PROCEDIMENTOS METODOLÓGICOS}

No primeiro momento da pesquisa efetuou-se uma revisão bibliográfica para o primeiro contato com o material de autores que discutem a temática proposta. Logo após realizou-se o levantamento documental para se conhecer a história e a atual realidade dos cursos de EAD oferecidos no município de São Gabriel do Oeste.

No terceiro momento, optou-se pela técnica da observação, uma vez que a primeira autora deste trabalho exerce a função de tutora, no município referenciado e mantém contato com diversos alunos de variados cursos, pois o local de encontro entre alunos e tutores é o mesmo para todos os cursos.

No quarto momento da pesquisa recorreu-se, ainda, ao questionário como técnica de coleta de dados. As autoras ressaltam que mesmo entendendo que essa é uma técnica que atende ao aspecto quantitativo(1), elegeram-na para facilitar o alcance ao objetivo da pesquisa, visto que assim, 
o aluno expressa suas ideias e expõe sua opinião sobre sua atuação como estudante em EAD.

Conforme orienta Lakatos (2001), verificou-se que os questionários poderiam ser entregues em dias aleatórios para atingir alunos de cursos diferentes e em variados graus de estudo formando, assim, um público com características diversificadas. Foi observado que a devolução dos questionários deveria ocorrer no próximo dia de atendimento tutorial.

Assim, foi realizada uma escolha aleatória de cinco alunos representados pelos símbolos $\mathrm{A} 1, \mathrm{~A} 2, \mathrm{~A} 3$, $\mathrm{A} 4$ e $\mathrm{A} 5$ - um aluno por turma dos cursos de Biologia, Matemática, Administração, Pedagogia - Séries Iniciais e Educação Especial. Foram feitas observações do perfil do aluno e a entrega do questionário.

Os questionários continham nove questões, quatro abertas e cinco fechadas, todas relacionadas às habilidades de autonomia no processo de ensino e de aprendizagem dos estudantes, objeto de estudo deste trabalho. Para efeitos deste artigo as autoras optaram por eleger apenas as principais questões que estão diretamente relacionadas às habilidades de autonomia.

A análise dos resultados teve por base a abordagem sóciointeracionista de Vygotsky (1994).

\section{Tabulação dos Dados e Análise}

\begin{tabular}{l|l} 
Sujeitos & Ano/ Curso \\
\hline Aluno 1= A1 & $1^{\circ}$ ano do curso de Matemática \\
\hline Aluno 2= A2 & $2^{\circ}$ ano do curso de Biologia \\
\hline Aluno 3= A3 & $1^{\circ}$ ano do curso de Administração \\
\hline Aluno 4= A4 & $\begin{array}{l}4^{\circ} \text { ano do curso de Pedagogia- Habilitação em séries } \\
\text { iniciais }\end{array}$ \\
\hline Aluno 5= A5 & $\begin{array}{l}1^{\circ} \text { ano do curso de Pedagogia- Habilitação em Educação } \\
\text { Especial } \\
\text { Quadro 1: dados coletados de alunos dos referidos cursos }\end{array}$
\end{tabular}




\begin{tabular}{l|l} 
Sujeitos & Respostas \\
\hline Aluno 1 & "Sim." \\
\hline Aluno 2 & "Sim." \\
\hline Aluno 3 & "Sim." \\
\hline Aluno 4 & "Sim." \\
\hline Aluno 5 & "Sim."
\end{tabular}

Quadro 2 - respostas dos alunos A1, A2, A3, A4 e A5 acerca da questão 2: Você se identifica com o curso que está fazendo?

\section{Análise das Respostas do Quadro 2}

Os alunos $A 1, A 2, A 3, A 4$ e $A 5$ expressaram que há identificação com o curso que estão fazendo. Isso evidencia que os estudantes estão motivados e interessados pelo curso que estão fazendo.

Sobre essa questão, Belloni (1999) e Preti (2000), discutem que a motivação e a participação do aprendiz são condições sine qua non do sucesso nos estudos em EaD, pois a medida que o aluno demonstra que gosta e se envolve com o curso, seu nível de conhecimento é consideravelmente aumentado.

\begin{tabular}{l|l} 
Sujeitos & Respostas \\
\hline Aluno 1 & "Sim." \\
& "Internet e livros." \\
\hline Aluno 2 & "Sim." \\
& "Internet e livros." \\
\hline Aluno 3 & "Sim." \\
\hline Aluno 4 & "Internet." \\
\hline Aluno 5 & "Internet e livros." \\
\hline "Sim."
\end{tabular}

Quadro 3 - resposta dos alunos A1, A2, A3, A4 e A5 acerca da questão 4: Você tem facilidade em fazer trabalhos de pesquisa? Quais as fontes que mais utiliza? 


\section{Análise das Respostas do Quadro 3}

Pelas respostas dos alunos constatou-se que todos possuem facilidade em fazer trabalhos de pesquisa e que a maioria utiliza a internet e os livros como fonte de informações.

Sabe-se que a educação com o apoio do computador é uma das referências em EAD e tem contribuído para a construção do processo de ensino e de aprendizagem nas mais variadas áreas do conhecimento. $A$ utilização dos sites é de grande ajuda para os estudantes de EAD, no entanto os livros precisam se fazer presentes, para também, auxiliar os estudantes, pois, nem todas as bibliografias são encontradas na internet.

\begin{tabular}{l|l} 
Sujeitos & Respostas \\
\hline Aluno 1 & $\begin{array}{l}\text { "Distancia, talvez um pouco de ausência de professores, se } \\
\text { aula fosse diariamente facilitaria mais." }\end{array}$ \\
\hline Aluno 2 & $\begin{array}{l}\text { "No início a ferramenta computador hoje realmente o } \\
\text { tempo escasso, curto para estudar." }\end{array}$ \\
\hline Aluno 3 & $\begin{array}{l}\text { "As matérias exatas, pois não temos um suporte é muito } \\
\text { difícil ter que aprender principalmente essas matérias." }\end{array}$ \\
\hline Aluno 4 & $\begin{array}{l}\text { "Talvez seja o pouco contato com os professores a maioria } \\
\text { responder." }\end{array}$ \\
\hline Aluno 5 & $\begin{array}{l}\text { "Algumas vezes no ambiente, ou seja, utilizar e usar o } \\
\text { ambiente e troca de idéias com os professores." }\end{array}$ \\
& \multicolumn{1}{c}{ maiores dificuldades no curso de EaD que freqüenta? }
\end{tabular}

\section{Análise das Respostas do Quadro 4}

A1, A4 e A5 citam que uma das dificuldades que enfrentam no curso a distância é a ausência ou o pouco contato com o professor. A5 complementa que tem dificuldade em utilizar o ambiente virtual de aprendizagem.

A2 comenta que a primeira dificuldade foi o uso do computador, mas afirmou que isso já foi resolvido, porém, persiste a dificuldade na organização do tempo.

A3 ressalta que tem dificuldades com alguns conteúdos específicos, alega que falta suporte para auxiliar no entendimento, mas, não comenta 
que tipo de suporte seria necessário.

Sobre a ausência e/ou pouco contato do professor com o aluno, Preti (2000) afirma que, os estudantes de EaD devem possuir confiança em si mesmos, em sua capacidade de aprender de maneira autônoma, sem depender passivamente do professor.

Quanto à dificuldade em utilizar o computador e a internet, possivelmente, se deve ao fato de que muitos alunos, especialmente, aqueles que têm maior idade, nunca manusearam esses recursos ou tiveram um mínimo contato com eles.

A essência do ensino a distância é o fato de ser mediado pelas tecnologias. Os alunos devem buscar por esse conhecimento para que possam efetuar o bom uso das ferramentas educacionais.

O tempo é um fator que realmente merece atenção na EAD. De acordo com Preti (2000), o aluno deve planejar o desenvolvimento dos conteúdos, observando o limite de tempo para isso. E conforme discute Belloni (2003), os estudos devem ser estabelecidos conforme o que foi definido e as rotinas da vida familiar não podem "quebrar ou amolecer" os compromissos assumidos.

As dificuldades com relação aos conteúdos específicos podem ser sanadas com uma maior busca pelo entendimento dos mesmos, seja por meio de pesquisa ou pelo contato com outras pessoas. Assim, um dos aspectos que influencia na facilidade do aprendizado, conforme destaca Preti (2000), é estar em atitude de aprendizagem e de interesse.

\begin{tabular}{l|l} 
Sujeitos & Respostas \\
\hline Aluno 1 & $\begin{array}{l}\text { "Mesmo sem ser conhecido como acadêmico proporciona } \\
\text { ensino superior aos alunos." }\end{array}$ \\
\hline Aluno 2 & $\begin{array}{l}\text { "Caminhar por suas próprias pernas, seja no uso da } \\
\text { internet, na pesquisa em livros, acertar com os erros." }\end{array}$ \\
\hline Aluno 3 & $\begin{array}{l}\text { "Aquele que mesmo não tendo um suporte, uma ajuda } \\
\text { consegue desenvolver suas atividades sem muito } \\
\text { sofrimento." }\end{array}$ \\
\hline Aluno 4 & "Ser um aluno autônomo é o aluno aprender sozinho." \\
\hline Aluno 5 & $\begin{array}{l}\text { "É aquele aluno que sempre consegue e tem facilidade de } \\
\text { entender a matéria, conseguindo notas e utilizando o } \\
\text { ambiente sem problemas." }\end{array}$
\end{tabular}


Quadro 5 - respostas dos alunos A1, A2, A3, A4 e A5 acerca da questão 9: Para você o que significa ser um aluno autônomo em educação a distância?

\section{Análise das Respostas do Quadro 5}

Nota-se que $A 1$, apesar de apresentar uma resposta um pouco confusa para o que lhe foi interrogado, deixa em evidência a questão do estudo em EAD ser sinônimo de isolamento e o fato do aluno estar "solitário" no processo de ensino e de aprendizagem, conforme ressalta Walker (1993) apud Belloni $(2003$, p. 47)

$\mathrm{Na}$ resposta do aluno é possível perceber que ele não se sente reconhecido como um acadêmico tradicional. Falta-lhe o sentimento de pertencimento e a integração na instituição onde estuda, já que o mesmo deseja algum tipo de reconhecimento.

Pode-se abstrair dessa colocação do aluno a questão discutida por Belloni (2003), que aponta para a maturidade e a motivação desse alunado, pois, se assim o fosse o aluno em estudo não precisava de reconhecimento.

A2, de forma indireta, consegue apresentar os aspectos desejáveis para ser um estudante autônomo em EAD. Belloni (2003, p. 40) cita vários autores que discutem a questão do aluno autônomo, gestor do seu processo de aprendizagem. Para o aluno referenciado, a flexibilidade é o aspecto mais importante, isso evidencia que ele se sente a vontade por ser um estudante da $E A D$, neste caso se aproxima do ideal esperado para esse alunado.

Na resposta de $\mathrm{A} 3$ fica subentendido a necessidade de apoio presencial, no entanto, é possível perceber que, mesmo parecendo necessitar desse apoio, ele sabe que em EAD o aluno autônomo deve ir em busca de conhecimento para então desenvolver suas atividades sem maior dificuldade.

O aluno A4 conseguiu de forma sucinta conceituar quem é o estudante autônomo, o que condiz com a afirmação de Belloni (2003, p. 42): "na aprendizagem autônoma, o estudante não é objeto ou produto, mas um sujeito ativo que realiza a sua própria aprendizagem".

$\mathrm{Na}$ opinião de $\mathrm{A} 5$, o processo de ensino e de aprendizagem se fundamenta na questão da nota, desse modo, o aluno não denotou possuir nenhum conhecimento sobre o real significado de estudante autônomo. 


\section{RESULTADO DAS ANÁLISES}

Pela análise dos resultados foi possível constatar habilidades relacionadas ao processo de ensino-aprendizagem e verificar a presença do perfil de estudantes autônomos em alguns dos alunos.

Análise do quadro 2. Nesse quadro todos os alunos responderam que se identificam com o curso que estão fazendo. Neste caso é possível notar que de alguma forma esses estudantes encontram-se motivados e interessados para a continuidade do curso. Em EAD a motivação é um elemento essencial, conforme nos apresenta Belloni (1999) e Pretti (2000) anteriormente mencionados.

A autora em referência apresenta ainda o ponto de vista de Trindade (1992), em que esse afirma que "adultos acham em si mesmos as motivações e as necessidades de aprender; [...].

Alunos motivados e interessados indicam possibilidade para às habilidades de aluno autônomo em seu processo de ensino aprendizagem.

Análise do quadro 3. Percebeu-se pelas respostas dos alunos que todos têm facilidade para realizar seus trabalhos de pesquisa com a utilização do computador. Moran (2002, p. 44) destaca que o computador "se converte em um meio de comunicação, a última grande mídia, ainda em estágio inicial, mas extremamente poderosa para o ensino e a aprendizagem".

Neste caso, parece que os alunos estão inteirados que seu processo de aprendizagem ocorre por meio da mediação homem/máquina, então podese afirmar que, de certa forma, estão motivados para realização de sua aprendizagem mediada pelo uso do computador. Isso evidencia aspectos que influenciam a capacidade de autonomia no processo de ensino e aprendizagem.

Análise do quadro 4. $\mathrm{Na}$ análise desse quadro, constata-se alguns pontos relevantes na implementação dos cursos de EAD, e que se apresentam como grandes desafios, tais como: a ausência do professor; dificuldade com o ambiente; dificuldade para entender conteúdos específicos. 
O que se pode perceber é que mesmo estudando na modalidade a distância, os alunos, insistem em fazer comparações com o ensino presencial ignorando o fato de que nessa nova forma de estudar, normalmente, o professor é substituído pelo tutor ou pelo orientador pedagógico.

Cabe ressaltar que esse profissional é o que terá maior proximidade com os estudantes da EAD, para tanto, ele precisa estar devidamente capacitado para poder oferecer o suporte pedagógico. Muitas vezes, porém, os estudantes, normalmente fazem suas reclamações porque não encontram o total apoio do tutor, buscam respostas e não encontram, sentem-se sozinhos e perdidos no curso, assim vem o abatimento e o desânimo.

Com relação às dificuldades com o ambiente, a segunda autora deste trabalho é coordenadora de cursos de EAD, e ressalta a questão dos encontros presenciais, os quais muitas vezes têm deixado a desejar quanto à orientação dos estudantes. Em vários momentos faltam planejamento e organização, ocorrendo inclusive problemas na utilização de ferramentas tecnológicas como data show e internet. A autora em referência entende que o encontro presencial de um curso é o "cartão de visita" do mesmo e tudo precisa estar em pleno funcionamento, devidamente conferido e organizado para que o estudante seja atendido em todas as suas necessidades.

Outro aspecto que precisa ser ressaltado é a disponibilidade do suporte técnico. Esse profissional ou essa equipe precisa estar integrada aos objetivos do curso, pois os alunos têm dúvidas corriqueiras, como a postagem de uma tarefa no ambiente entre outras.

Quanto às dificuldades de clareza no estudo de conteúdos específicos, o curso precisa ter disponível uma boa equipe pedagógica, oferecendo também, uma constante atualização de conhecimentos.

Nota-se assim, que se a estrutura do curso não for satisfatória não há como esperar que o aluno desenvolva as habilidades de autonomia em seu processo de aprendizagem.

Análise do quadro 5. Nesse quadro percebe-se que dos cinco estudantes que participaram da pesquisa, A1 - abordou um aspecto delicado em EAD, o aluno solitário; Belloni 2003 e Preti (2000) tratam dessa questão.

Um dos problemas que a Educação a Distância enfrenta é o isolamento físico e geográfico do aluno e do tutor. Para estabelecer um contato mais próximo, facilitando o processo ensino-aprendizagem e viabilizando uma prática educativa 
A2 e A3 e A4 descreveram de forma satisfatória o conceito de aluno autônomo. Talvez o que mais tenha se aproximado do conceito ideal seja o aluno $A 2$, enquanto $A 5$ demonstrou não conhecer o significado de autonomia no processo de ensino e de aprendizagem em EAD.

$\mathrm{Na}$ análise desse quadro constata-se a proximidade com a afirmação de Belloni (2003, p. 42), quando ressalta que estamos longe de atingir o ideal para os alunos de EAD. Na discussão da autora fica evidente que apesar de todos os esforços envidados por instituições mantenedoras de cursos a distância talvez o maior desafio seja o de trabalhar a questão da autonomia no processo de ensino e de aprendizagem de seus estudantes.

A autora em referência vai mais além quando afirma que:

"o aprendiz atualizado é um mito, e muitos estudantes encontram dificuldades para responderem às exigências de autonomia em sua aprendizagem, dificuldade de gestão do tempo, de planejamento e de autodireção colocados pela aprendizagem autônoma (BELLONI, 2003, p. 45)

Conforme afirmação dos autores e pelas análises das respostas dos cinco estudantes que participaram da pesquisa, pôde-se constatar que apenas três alunos apresentaram algumas das habilidades que vão ao encontro dos conceitos estabelecidos para o aprendiz autônomo em EAD. Dessa forma identifica-se que do ideal desejado para os alunos em EAD, no município em estudo, apenas os alunos A2, A3 E A4 apresentam habilidades que denotam autonomia parcial no processo de aprendizagem.

\section{CONSIDERAÇÕES FINAIS}

É notável a importância de mostrar ao aluno quando ele ingressa em um curso de graduação em EAD, as características dessa modalidade, bem como, o que se espera desse estudante, especialmente, em relação às habilidades de autonomia. Assim, orientados no início do curso, os estudantes poderão apresentar um perfil de maior autonomia no desenvolvimento de seus estudos. 
$\mathrm{Na}$ discussão dos autores percebe-se que para eles os aspectos que envolvem a questão das habilidades de autonomia no processo de ensino e aprendizagem dos alunos de EAD, ainda é um mito, fica apenas no ideal.

$\mathrm{Na}$ pesquisa realizada, e na análise dos resultados, constatou-se que três dos alunos envolvidos apresentam algumas das habilidades que os identificam como estudantes autônomos. Desse modo, considera-se que nenhum dos alunos entrevistados é totalmente autônomo em seus estudos, pois parece faltar aos mesmos assumirem compromissos e mudar atitudes na rotina de estudantes de EAD.

Referente à pesquisa, ressalta-se que o estudo realizado no município de São Gabriel do Oeste foi inicial. Existe a necessidade de dar continuidade, abrangendo outros cursos e um número maior de alunos para se ter uma dimensão mais ampla do objeto estudado: a autonomia dos alunos de EAD em seu processo de ensino e de aprendizagem.

\section{Referências}

BELLONI, M. L. Educação a distância. Campinas: Autores Associados, edição: 1999 e 2003.

LAKATOS, E.M; MARCONI, M.A. Fundamentos de Metodologia Científica. 3.ed. ampl. SP:Atlas, 1991, p. 201.

LIMA, M.C. Monografia: a engenharia da produção acadêmica. SP, Saraiva, 2004.

MORAN, J. M. $O$ que é educação a distância. Atualizado em: 2002. Acesso em: 30 out. 2008. Disponível em: http://www.eca.usp.br/prof/moran/dist.htm

PRETI, O. Autonomia do aprendiz na educação a distância. In: PRETI, O. (org). Educação a Distância: construindo significados. Cuiabá: NEAD/ IE- UFMT. Brasília: Plano, 2000.

VYGOTSKY. L, S. A formação Social da Mente. Martins Fontes, São Paulo, 1994. 
Nota de Referência

Alguns erros de ortografia foram mantidos em obediência às respostas dos alunos.

1 LIMA, M.C. Monografia: a engenharia da produção acadêmica. SP. Saraiva, 2004, p. 52. 